\title{
Corrigendum
}

\section{The Importance of Iatrogenesis in the Founding of Modern Neonatology}

Billy F. Andrews, MD, FAAP, FACP, FRSM

Journal of Perinatology (2004) 24, 802. doi:10.1038/sj.jp.7211218

Correction to: Journal of Perinatology (2004) 24, 671-673, doi:10.1038/jp.7211161

Following publication of the above paper, the author has realized that two figures pertinent to the article were left out. The figures as they should appear are below. These cartoons have been used in numerous articles and books in the last half century.

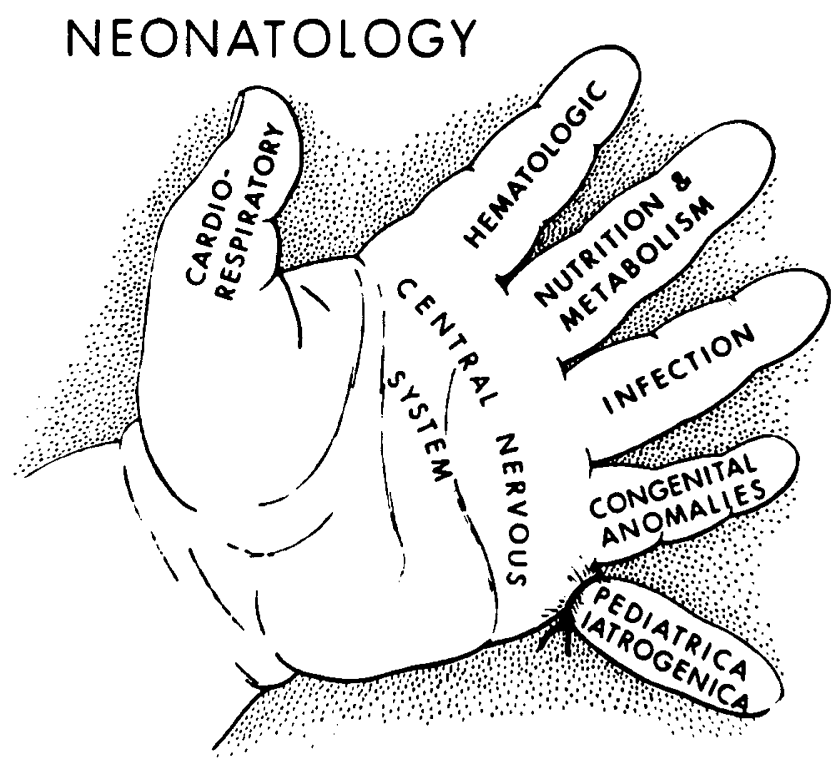

Figure 1. Andrews BF. Six finger exercise. Am J Dis Child 1968; $116: 334$

\section{THE "SMALL FOR DATE" BABY}

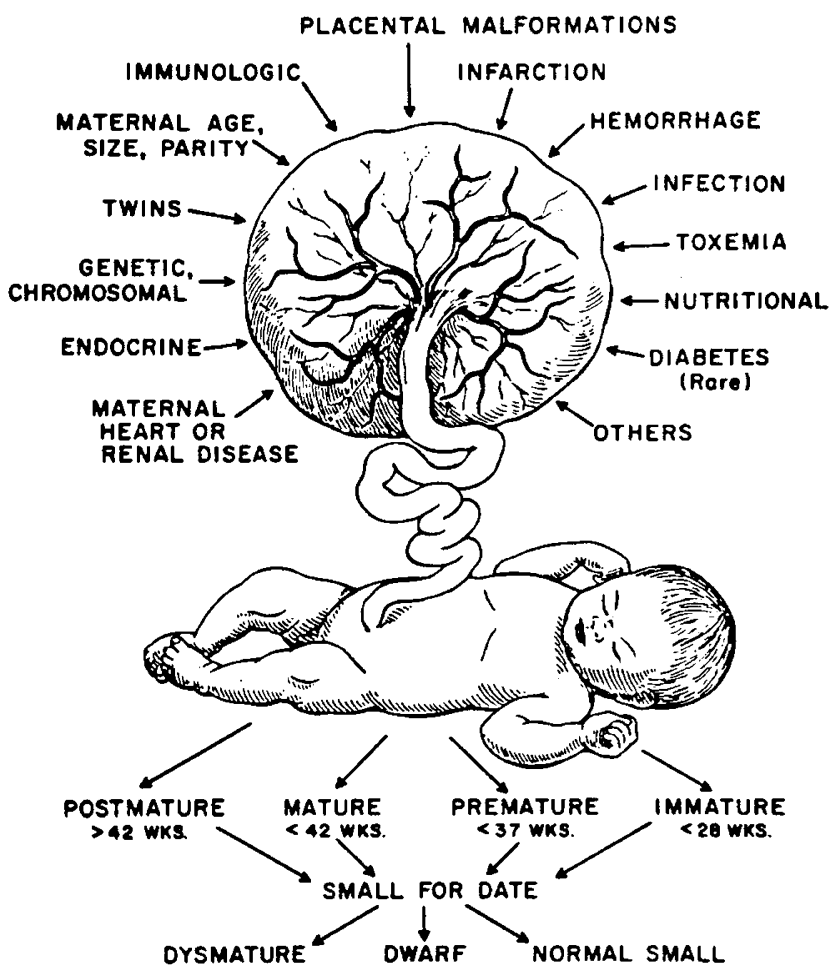

Figure 2. Andres BF, editor. The small-for-Date Infant. Philadelphia: WB Saunders; 1970, p. 185-98. 